\title{
Relation between stratospheric sudden warming and the lunar effect on the equatorial electrojet based on Huancayo recordings
}

\author{
T. A. Siddiqui ${ }^{1,2}$, H. Lühr ${ }^{1}$, C. Stolle ${ }^{1,2}$, and J. Park ${ }^{1, *}$ \\ ${ }^{1}$ Helmholtz Centre Potsdam, GFZ - German Research Centre for Geosciences, Potsdam, Germany \\ ${ }^{2}$ University of Potsdam, Institute of Earth and Environmental Science, Potsdam, Germany \\ * present address: Solar and Space Weather Research Group, Korea Astronomy and Space Science Institute (KASI), Daejeon, \\ Republic of Korea
}

Correspondence to: T. A. Siddiqui (tarique@gfz-potsdam.de)

Received: 21 September 2014 - Revised: 23 January 2015 - Accepted: 29 January 2015 - Published: 26 February 2015

\begin{abstract}
It has been known for many decades that the lunar tidal influence in the equatorial electrojet (EEJ) is noticeably enhanced during Northern Hemisphere winters. Recent literature has discussed the role of stratospheric sudden warming (SSW) events behind the enhancement of lunar tides and the findings suggest a positive correlation between the lunar tidal amplitude and lower stratospheric parameters (zonal mean air temperature and zonal mean zonal wind) during SSW events. The positive correlation raises the question whether an inverse approach could also be developed which makes it possible to deduce the occurrence of SSW events before their direct observations (before 1952) from the amplitude of the lunar tides. This study presents an analysis technique based on the phase of the semi-monthly lunar tide to determine the lunar tidal modulation of the EEJ. A statistical approach using the superposed epoch analysis is also carried out to formulate a relation between the EEJ tidal amplitude and lower stratospheric parameters. Using these results, we have estimated a threshold value for the tidal wave power that could be used to identify years with SSW events from magnetic field observations.
\end{abstract}

Keywords. Ionosphere (electric fields and currents) - meteorology and atmospheric dynamics (waves and tides)

\section{Introduction}

The equatorial electrojet (EEJ) is a narrow band of intense electric current flowing in the eastward direction above the magnetic dip equator in the daytime $\mathrm{E}$ region of the ionosphere. The electrojet is a Hall current which is driven by the large vertical electric field set up at the dip equator (Stening, 1995). The influence of the lunar tides on the EEJ has been known for a long time. Bartels and Johnston (1940) carried out the initial study of the lunar influence on the EEJ and they reported the existence of "big L" days between the months November to March at Huancayo in Peru. During these days they observed that the lunar daily variations in the horizontal component of the magnetic field get considerably enhanced compared to normal days. This similar enhancement was then reported at other equatorial observatories (e.g. Kodaikanal, Egedal, 1956; Ibadan, Onwumechilli, 1960; Addis Ababa, Gouin, 1960). Rastogi and Trivedi (1970) discussed the seasonal variation of lunar tides within the EEJ at several equatorial observatories. Lühr et al. (2012) presented a comprehensive overview of lunar tides in the EEJ using the data from the CHAMP satellite. All of these studies confirmed the enhanced tidal amplitudes around the December solstice.

It has been proposed in recent years that this noticeably enhanced lunar tidal effect in the EEJ during northern winters coincides with stratospheric sudden warming (SSW) events. The phenomenon of SSW was first observed by Scherhag (1952) and since then it has been studied quite extensively. An SSW is a large-scale meteorological event characterized by the weakening of the westerly winds in the northern stratosphere and a breakdown of the polar vortex which leads to a sudden rise in the polar stratospheric temperature by several tens of degrees (e.g. Andrews et al., 1987). Matsuno (1971) proposed the non-linear interaction of the vertically propagating planetary waves with the zonal mean flow as the key mechanism for generating SSWs. The effects of SSW are not only restricted to the stratosphere but also extend into the 
ionosphere. Therefore, SSW is sometimes regarded as one of the most important large-scale meteorological phenomena (e.g. Chau et al., 2012).

Recent literature has debated whether SSW events facilitate the lunar tidal propagation which in turn leads to enhanced tidal amplitudes around the December solstice (e.g. Fejer et al., 2010, 2011; Stening, 2011; Park et al., 2012; Yamazaki et al., 2012a, b). Stening (2011) pointed out that the relation between the large lunar tide in EEJ and SSW events could be coincidental, while Park et al. (2012) confirmed a one-to-one correspondence between the lunitidal enhancement at ionospheric heights and the occurrence of SSW events between 2001-2009. Likewise, Yamazaki et al. (2012a) investigated the correlation between the amplitude of the geomagnetic lunar tide at Addis Ababa and lower stratospheric parameters and confirmed the occurrence correspondence between SSWs and the enhancement of the geomagnetic lunar tide for the majority of years between 1958-2007. However, their report contains counter-examples during January 1983 and January 1985 where the occurrence correspondence breaks down.

The purpose of this paper is an attempt to deduce the occurrence of SSWs for the times before their direct observations (before 1952). For achieving this goal we make use of magnetic field recordings of the Huancayo observatory, which is located under the magnetic equator. The observatory started recordings in 1922.

In the following sections we first describe the various data sets used in this study (in Sect. 2). In Sect. 3 we introduce our approach for determining the strength of the lunar tidal modulation of the equatorial electrojet. In Sect. 4 results are presented. We start with the years past 1952 and make direct comparison with stratospheric observations of the SSWs. Afterwards we also show EEJ lunar modulations from time before SSW observations. Section 5 provides a discussion of our results in comparison to related studies. Furthermore, we provide a statistical assessment of the relation between SSW parameters and lunar tidal amplitude and make predictions of SSW events derived from lunar tides in magnetic data. Results are summarized in Sect. 6.

\section{Data set}

The choice of the observatories is based on the fact that we want to monitor the variation of the EEJ as far back into the past as possible. In addition, we require that one of the observatories lies within the electrojet zone and the other lies outside of it. The purpose of this approach is that a major part of magnetospheric variation at an equatorial observatory can be removed by considering variations at a non-equatorial observatory (e.g. Manoj et al., 2006). Thus the observatories Huancayo, HUA $\left(-12.05^{\circ} \mathrm{N}, 284.67^{\circ} \mathrm{E}\right)$ and San Juan, SJG $\left(18.11^{\circ} \mathrm{N}, 293.85^{\circ} \mathrm{E}\right)$ constitute one such pair. The latitudinal difference between the Huancayo-San Juan pair is $30.16^{\circ}$ while the longitudinal difference between the stations is $9.18^{\circ}$. San Juan serves as a reference station to the equatorial station at Huancayo for eliminating the effects of largescale magnetospheric fields. The San Juan magnetic observatory has a continuous data record of hourly means of the horizontal component of magnetic field since 1926. On the other hand, the hourly means recorded at the Huancayo observatory are available from 1922 onwards; however, there are some lengthy durations of missing data for the periods 1962-1963, 1970-1978, 1981-1984 and 1991-1996. Here we use the data available between the years 1926 to 2009 for the Huancayo and the San Juan observatories to determine the lunar tides.

We employ the hourly means of the geomagnetic horizontal field component from these two magnetic observatories in our study. The data were downloaded via the website of the World Data Centre (WDC) for Geomagnetism, Edinburgh.

To consider the effects of solar activity on the EEJ strength we use the solar flux values $F_{10.7}$ in sfu $\left(10^{-22} \mathrm{~W} \mathrm{~m}^{-2} \mathrm{~Hz}^{-1}\right)$ which are available since 1947 on the website of the Dominion Radio Astrophysical Observatory in Penticton, British Columbia, Canada. For earlier years we use the sunspot numbers which are available since 1818 and can be downloaded from the website of WDC-SILSO, Royal Observatory of Belgium, Brussels.

For identifying the SSW events, daily mean values of the zonal mean temperature at 60 and $90^{\circ} \mathrm{N}$ at the $10 \mathrm{hPa}$ level and daily means of the zonal mean zonal wind at $60^{\circ} \mathrm{N}$ and at $10 \mathrm{hPa}$ level were obtained from the reanalysis data of the National Centers for Environmental Prediction/National Center for Atmospheric Research (NCEP/NCAR) (Kalnay et al., 1996) for the years 1948 to 2010.

\section{Method of analysis}

The total magnetic field variation at the dip equator includes the contributions from the EEJ, magnetospheric and Sq current systems and it is proportional to $\left(j_{H}+j_{P}\right)$ where $j_{H}$ and $j_{P}$ are the Hall and Pedersen currents, respectively. In this paper, we follow the assumption that the magnetic signature of the electrojet on ground, $H_{\mathrm{EEJ}}$, is proportional to $j_{H}$. For the horizontal magnetic field component, $H$, we can write

$H=H_{\mathrm{MF}}+H_{\mathrm{MP}}+H_{\mathrm{Sq}}+H_{\mathrm{EEJ}}$,

where $H_{\mathrm{MF}}$ is the main field, $H_{\mathrm{MP}}$ the field of magnetospheric currents (e.g. ring current), $H_{\mathrm{Sq}}$ the field of largescale ionospheric currents and $H_{\mathrm{EEJ}}$ the magnetic effect of the electrojet. To calculate the intensity of the magnetic field that is only due to the effect of the electrojet, the first three terms on the right-hand side have to be removed. An estimate for the main field, $H_{\mathrm{MF}}$, is obtained from the quiet night-time values. For both stations we first calculate

$\Delta H=H-H_{\mathrm{MF}}$. 
For the isolation of the electrojet effect we assume that large-scale fields of magnetospheric currents are the same at both observatories (e.g. Stolle et al., 2008). The EEJ strength is estimated from an observatory pair by evaluating the difference of the horizontal intensities $\Delta H$ at the two locations as

$H_{\mathrm{EEJ}}=\Delta H_{\mathrm{HUA}}-\Delta H_{\mathrm{SJG}}$.

The strength of the EEJ currents shows a linear relationship with the solar activity (Alken and Maus, 2007). Stronger EEJ currents are recorded during periods of solar maximum and vice versa. In order to take into account also the resulting day-to-day variability caused by EUV radiation, the effects of solar activity on the EEJ are normalized with the help of $F_{10.7 P}$ where $F_{10.7 P}=\frac{F_{10.7}+F_{10.7 A}}{2}$ (Richards et al., 1994). $F_{10.7}$ is the observed value of solar radio emission at $10.7 \mathrm{~cm}$ for each day and $F_{10.7 A}$ is the 81-day centred mean of $F_{10.7}$. As the $F_{10.7}$ readings are available only since 1947 , we make use of the recordings of the sunspot numbers for normalization before 1947.

For the correction of the solar flux dependence we apply the relation deduced by Alken and Maus (2007) for their EEJM model. They propose the linear relation

$J=4.458 \times 10^{-5}\left(\mathrm{Am}^{-1}\right) E+0.040\left(\mathrm{Am}^{-1}\right)$,

where $J$ is the height-integrated peak current density of the EEJ in $\mathrm{A} \mathrm{m}^{-1}$ and $E$ is the EUVAC (Extreme UltraViolet flux model for Aeronomic Calculations) value, which is practically identical with our $F_{10.7 P}$ readings. It was shown by Manoj et al. (2006) that the EEJ peak current density estimated from the CHAMP satellite is highly correlated with the EEJ intensity derived from a ground observatory $\left(H_{\mathrm{EEJ}}\right)$. We normalized all our $H_{\mathrm{EEJ}}$ values to a solar flux value of $F_{10.7 P}=150 \mathrm{sfu}$. However, since the solar flux index $F_{10.7}$ is available only since 1947 , we had to use an alternative for normalizing the solar activity influence before 1947. Our EUVAC index $E$ in Eq. (4) is in this case based on the sunspot number. Based on a correlation analysis using the data from the years 1960-2009 we could establish a linear relation between the $F_{10.7}$ and the sunspot number:

$F_{10.7}=\frac{\text { sunspot number }+62.58}{1.03}$

The dominant variation of $H_{\mathrm{EEJ}}$ is the diurnal variation, but we are interested in the lunar tidal modulation of that signal. In order to suppress the daily wave, the data are sorted into bins of 1 day by $1 \mathrm{~h}$ in Local Time (LT) for two synodic months (59 days). The effect of solar tides is removed by subtracting the mean over the 59-day period for each local time hour from the bin averages. Figure 1 shows an example of this processing approach. The top frame shows the $H_{\text {EEJ }}$ obtained from the Huancayo-San Juan pair before removing the dominant diurnal variation and the bottom frame shows
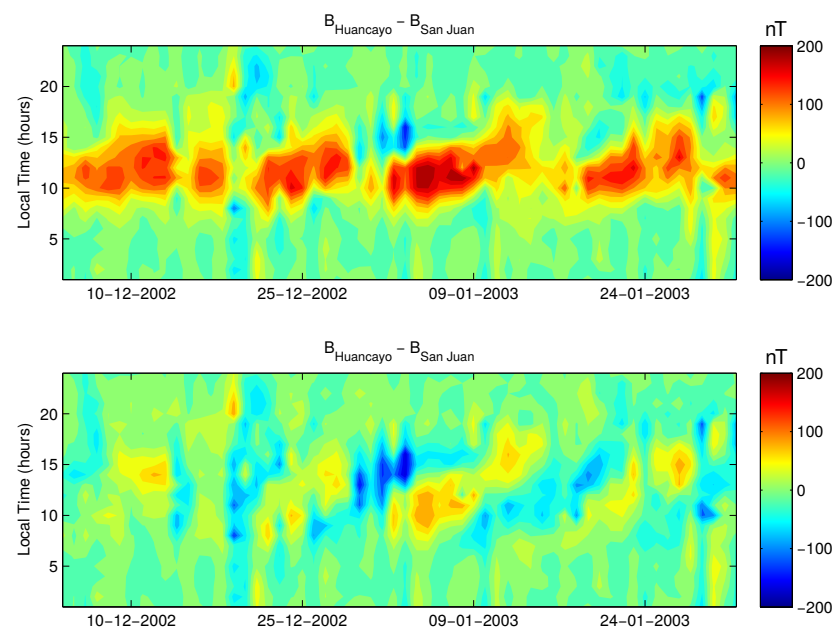

Figure 1. The top frame shows $H_{\text {EEJ }}$ obtained from the HuancayoSan Juan pair during December 2002-January 2003 before removing the solar tidal effects. The bottom frame shows the same plot after the removal of solar tidal effects.

the similar plot after removing the diurnal variation. The local time sector considered here is from 07:00 to 17:00 LT. Outside of this time interval the EEJ signal is considered to be weak. Each data set for analysis starts with the day of the new moon phase and ends on the day before the new moon. A sliding window of 59 days advanced by one synodic month is applied for each subsequent data set, as this overlap ensures improved amplitude resolution. We apply harmonic analysis for each local time hour over the period of two synodic months (59 days) for a quantitative investigation of the lunar signal. The frequency of interest is the fourth harmonic signal (semi-monthly wave) for which both the phase $\left(\phi_{\text {obs }}\right)$ and the amplitude $(a)$ are determined for each local time hour. We use the relation described by Lühr et al. (2012) to predict the phase of the semi-monthly lunar tide as a function of the lunar age $(d)$ and local time (LT). The lunar age is taken as the number of days, $d$, since new moon:

$\mathrm{LT}=0.98\left(d-d_{0}\right)+8.5 \mathrm{~h}$,

where $d_{0}$ is calculated by converting the moon phase of $12 \mathrm{~h}$ in terms of lunar age. As the moon phase of $24 \mathrm{~h}$ corresponds to lunar age of 29.53 days, the moon phase of $12 \mathrm{~h}$ can be calculated to correspond to lunar age of 14.76 days.

The lunar tide is an astronomical phenomenon. Therefore its phase is well known. We take advantage of this a posteriori information for our analysis. The expected phase, $\phi_{\text {pre }}$, of the lunar wave can be obtained by using the relation for each local time hour

$\phi_{\text {pre }}=\frac{\pi}{6 \mathrm{~h}}(\mathrm{LT}-12 \mathrm{~h})+\phi_{0}$,

where $\phi_{0}$ is the angle (in radians) corresponding to the common delay of 4.4 days from the new moon day until the tidal 
wave crest reaches $12 \mathrm{~h}$ local time, as described by Park et al. (2012). The value of the phase $\left(\phi_{\text {pre }}\right)$ is used as the expected phase and compared with the value obtained from the harmonic analysis.

We define a parameter $\epsilon$ as

$\epsilon=\phi_{\text {obs }}-\phi_{\text {pre }}$.

The cosine of the difference between the computed and the observed phase values is used as a weighting function and it has been determined experimentally:

$a^{\prime}=a \cos \epsilon \quad$ for $|\epsilon|<\frac{\pi}{2}$.

We use a filtering condition that if $|\epsilon|>\frac{\pi}{2}$, then the derived amplitude and the phase for that local time is not considered. A value lower than $\frac{\pi}{2}$ could also be chosen but then it would result in fewer wave amplitude values. The wave amplitude $\left(a^{\prime}\right)$ obtained is then divided by the sum of weights.

We further normalize the amplitude for the expected diurnal variation of the ionospheric conductivity, " $C$ ", as described by Lühr et al. (2008). Their assumption is based on the fact that the electron density of the E layer varies proportional to the square root of the cosine of the solar zenith angle. The diurnal variation of the ionospheric conductivity does not only influence the Sq currents but also the amplitude of the lunar tidal signal, as has been shown by Lühr et al. (2012). Without the normalization, the values around noon would dominate the tidal results:

$C=C_{0} \sqrt{\cos \left\{\frac{\pi}{12 \mathrm{~h}}\left(\mathrm{LT}-t_{0}\right)\right\}}$,

where $C_{0}$ is the value of the peak conductivity and $t_{0}$ is the local time of the peak conductivity. A suitable value for $t_{0}$ has been found to be 12:30LT. For our purpose we chose $C_{0}$ to be equal to 1 .

In the determination of the mean amplitude, $A$, over the two synodal months the lunar phase propagation from hour to hour is taken into account. The semi-monthly lunar tidal amplitude, $A$, is obtained by comparing the coefficients in Eq. (11) where $\omega$ is the angular frequency given by $\left(\frac{2 \pi}{59}\right.$ day $\left.^{-1}\right), t$ denotes time in days and $\phi_{\text {mean }}$ denotes the phase of the mean lunar tidal wave computed for 07:00 to 17:00 LT:

$A \cos \left(4 \omega t-\phi_{\text {mean }}\right)=\frac{1}{11} \sum_{\mathrm{LT}=7}^{17} \frac{a^{\prime}(\mathrm{LT})}{C} \sum_{\mathrm{LT}=7}^{17} \beta$,

where

$\beta=\cos \left(4 \omega t-\phi_{\mathrm{obs}}(\mathrm{LT})+\epsilon\right)$.

The amplitude $A$ is given in nT. For every lunar month we compute one value.

\section{Observation}

It has been observed that the influence of the lunar tide on the EEJ intensity is generally quite small except during certain "big L days" which were reported by Bartels and Johnston (1940). During these days the lunar tidal influence is much more prominent. Figure 2 shows two examples of the diurnal magnetic field variations underneath the EEJ from the Huancayo observatory. On the left side (top) we see a 2-month period from a non-SSW winter where the tidal effects are weak while the figure on the right (top) corresponds to the EEJ variation with a prominent lunar tidal modulation during an SSW winter. The dashed lines mark the expected lunar tidal wave propagation with local time from day to day, which fits very well with the observed tidal wave crests. We plot the difference between the stratospheric temperature at the North Pole $\left(90^{\circ} \mathrm{N}\right)$ and the zonal mean temperature from $60^{\circ} \mathrm{N}$, both at $10 \mathrm{hPa}$ in the middle panels and the difference between the zonal mean zonal wind $\left(U_{60}\right)$ at $60^{\circ} \mathrm{N}$ and $10 \mathrm{hPa}$ from the climatological mean $\left(U_{C}\right)$ in the bottom panels to explain the different response of the EEJ signal during the two periods.

It can be observed that on the left side the temperature difference between the two latitudes is quite constant but there is a fairly large variation on the right side. This variation in temperature difference is due to a SSW event. Therefore it can be clearly seen that SSW events coincide with an amplification of the lunar tidal effect on the EEJ.

The definition of a major SSW event according to the World Meteorological Organization (WMO) involves the reversal of the latitudinal temperature gradient poleward of $60^{\circ} \mathrm{N}$ and the reversal of the zonal mean zonal wind at $60^{\circ} \mathrm{N}$ at $10 \mathrm{hPa}$. The criterion for a minor warming event is the increase in the stratospheric polar temperature by $25 \mathrm{~K}$ or more within a week and involves no reversal of the zonal mean zonal wind. However, here we follow the definition adopted by Yamazaki (2013) in which an SSW winter is identified if the zonal mean zonal wind at $60^{\circ} \mathrm{N}$ and $10 \mathrm{hPa}$ shows a significant change from the climatology $\left(U_{60}-U_{C}<\right.$ $-20 \mathrm{~m} \mathrm{~s}^{-1}$ ), and there is a significant reversal in the temperature gradient $\left(T_{90}-T_{60}>10 \mathrm{~K}\right)$ during December-February. The readers may refer to Yamazaki (2013) for more details on the definition. We determine the climatology $\left(U_{C}\right)$ for the zonal mean zonal wind by calculating the mean value from 1948 to 2010 at each day of the year. We list the dates of all the SSW (peak warming) events obtained using this definition for 1952-2009 in Table 1.

We hereafter refer to the difference between the temperature at the North Pole $\left(90^{\circ} \mathrm{N}\right)$ and the zonal mean temperature at $60^{\circ} \mathrm{N}$, both at $10 \mathrm{hPa}$, as the zonal mean temperature gradient.

In Fig. 3, the top frame shows the wave power of the lunar tides obtained according to Eq. (11) from the HuancayoSan Juan pair, the middle frame shows the zonal mean temperature gradient for the period 1952-1962 and the bottom 

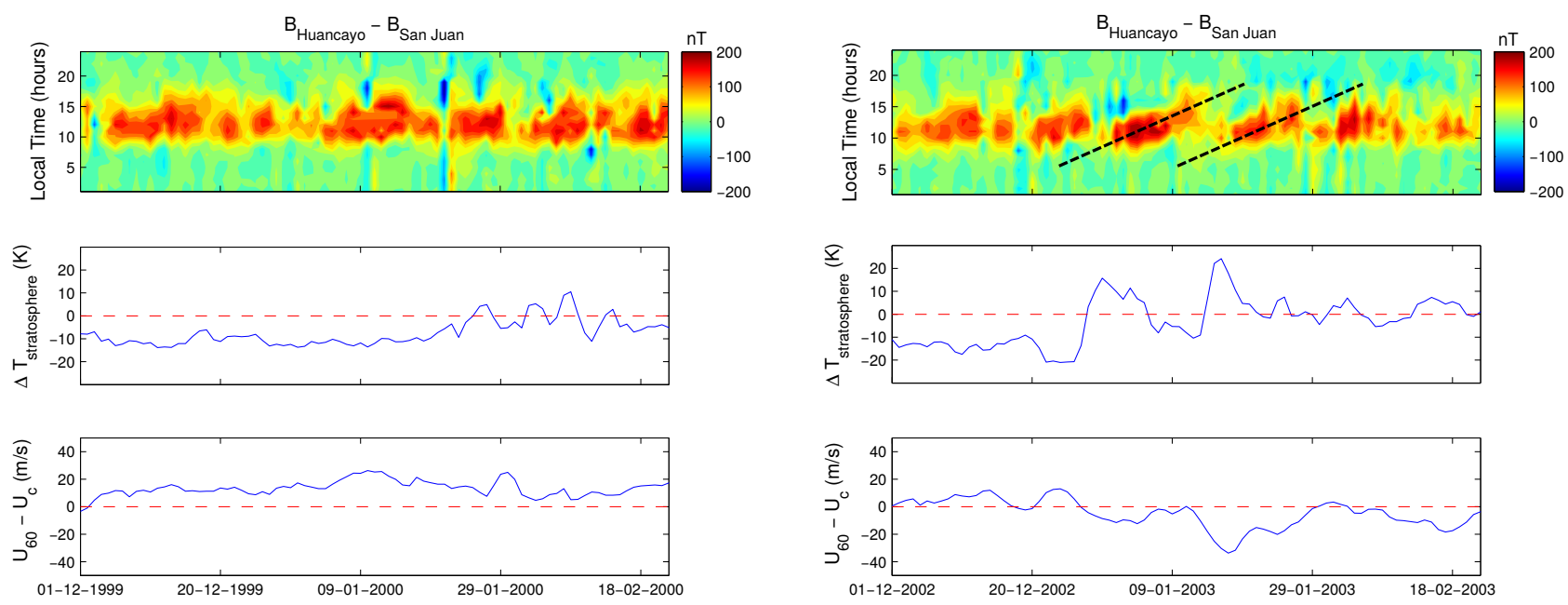

Figure 2. The top panels show the diurnal variation of the EEJ intensity (nT) as observed at Huancayo. The middle panels show the temperature difference in the stratosphere between the polar region and $60^{\circ} \mathrm{N}$ latitude at $10 \mathrm{hPa}$. The bottom panels show the deviation of the zonal mean zonal wind at $60^{\circ} \mathrm{N}$ and at $10 \mathrm{hPa}$ from the climatological mean. The left figure (top) shows the EEJ variation on normal days with weak lunitidal effect while the figure on the right (top) corresponds to the EEJ variation during an SSW event. The lines in the top right panel mark the expected lunar tidal wave propagation in local time.
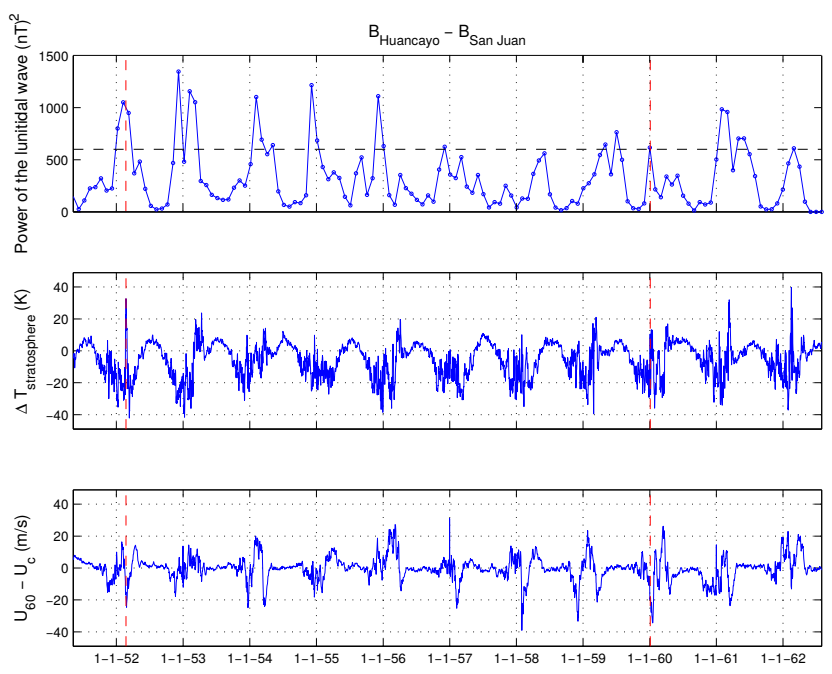

Figure 3. The top frame presents the wave power of the lunar tide derived from the Huancayo-San Juan pair for the years 1952-1962. The middle frame shows the zonal mean temperature gradient for the same period. The bottom frame shows the difference between the zonal mean zonal wind $\left(U_{60}\right)$ at $60^{\circ} \mathrm{N}$ and $10 \mathrm{hPa}$ from the climatological mean $\left(U_{C}\right)$. The red lines mark the days of SSW (peak warming) events and the black dashed line in the top panel denotes the threshold level calculated for classifying SSW and non-SSW years.

frame shows the difference between the zonal mean zonal wind $\left(U_{60}\right)$ at $60^{\circ} \mathrm{N}$ and $10 \mathrm{hPa}$ from the climatological mean $\left(U_{C}\right)$. The red lines denote the days of SSW (peak warming) events. Though the SSW events of February 1952 and January 1960 show enhanced lunar tidal powers, we do not ob- serve a one-to-one correspondence between the reversal of the temperature gradient and the enhancement of the lunar tidal power during this period. During November 1952 and December 1954, there is a significant deviation of $U_{60}$ from $U_{C}$ reaching close to $-20 \mathrm{~m} \mathrm{~s}^{-1}$ but $T_{90}-T_{60}<10 \mathrm{~K}$ during this time. During March 1953, a significant increase in the temperature gradient can be observed but there is no prominent deviation in the zonal mean zonal wind from climatology. However, the lunar tidal enhancements can be seen during all these times. Similarly, this behaviour can also be seen during December 1953 and February 1962 when only one of the parameter satisfies the SSW criteria. However, during January 1958 no such enhancements are observed even though $U_{60}-U_{C}<-20 \mathrm{~m} \mathrm{~s}^{-1}$. The lunar tides are also enhanced during March 1959 and 1961 when both the SSW criteria are satisfied. We also observe some counter-examples like during December 1955 where the lunar tidal power increases without any of the SSW criterion being satisfied. These examples suggest there are also other physical processes behind the enhancement of the lunar tides that are not addressed by this definition of SSW. Yamazaki et al. (2012a) also reported some cases where no correspondence was observed. We suggest that further clarifications in the definition of an SSW event might improve the correlation between the lunar tidal enhancements and the lower stratospheric parameters.

The next set of continuous data records available for the Huancayo observatory and with much improved quality starts from 1997. In Fig. 4 we show the same parameters as in Fig. 3 for the period 1997-2009. A much clearer lunitidal signature is obtained for this duration. Periods of SSW events are much better confined and the ratio in signal power is im- 
Table 1. SSW events of 1952-2009 identified using NCEP/NCAR reanalysis data. The definition used to identify SSW events is described in Sect. 4.

\begin{tabular}{|c|c|}
\hline Number & SSW events (peak warming) \\
\hline 01 & 23 Feb 1952 \\
\hline 02 & 3 Jan 1960 \\
\hline 03 & 10 Dec 1965 \\
\hline 04 & 7 Jan 1968 \\
\hline 05 & 7 Dec 1968 \\
\hline 06 & 29 Dec 1969 \\
\hline 07 & 10 Jan 1971 \\
\hline 08 & 30 Jan 1973 \\
\hline 09 & 2 Jan 1974 \\
\hline 10 & 15 Dec 1976 \\
\hline 11 & 21 Dec 1978 \\
\hline 12 & 27 Feb 1979 \\
\hline 13 & 5 Feb 1981 \\
\hline 14 & 28 Jan 1982 \\
\hline 15 & 19 Jan 1987 \\
\hline 16 & 10 Dec 1987 \\
\hline 17 & 12 Feb 1989 \\
\hline 18 & 27 Jan 1991 \\
\hline 19 & 19 Jan 1992 \\
\hline 20 & 2 Jan 1994 \\
\hline 21 & 29 Jan 1995 \\
\hline 22 & 27 Dec 1997 \\
\hline 23 & 19 Dec 1998 \\
\hline 24 & 20 Dec 2000 \\
\hline 25 & 25 Dec 2001 \\
\hline 26 & 17 Jan 2003 \\
\hline 27 & 28 Dec 2003 \\
\hline 28 & 23 Jan 2006 \\
\hline 29 & 23 Feb 2008 \\
\hline 30 & 23 Jan 2009 \\
\hline
\end{tabular}

proved between periods of SSW events and other times. All the SSW events between 1997 and 2009 except 2001 show enhanced lunar tidal powers.

Since common data sets for observatories Huancayo and San Juan are available from 1926 onwards, we computed the lunar tidal wave power in the same way as before for these earlier years. Figures 5 and 6 show the lunar wave power for the years 1926-1938 and 1939-1951, respectively. We again find clear peaks around the beginning of the years and minimum values during the middle of the years. The annual variation is partly not so clear for the early years up to 1932 . During that time span repeatedly data gaps are encountered that may have compromised the results. For the rest of the time, values consistent with our assumption are derived for the modulation of the EEJ amplitude. For these early years the zonal mean air temperature values from high latitudes are not available.
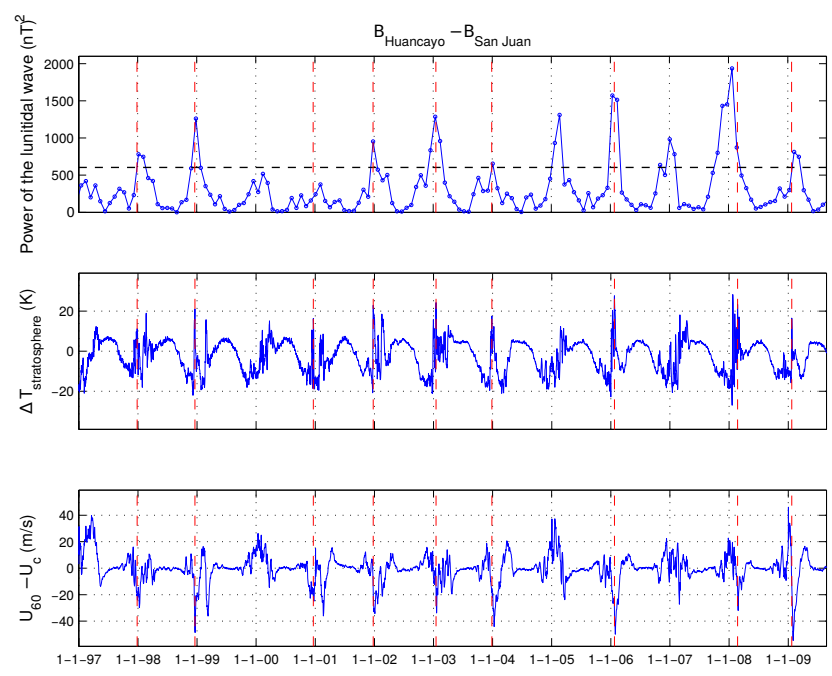

Figure 4. As Fig. 3, but for the period 1997-2009.

\section{Discussion}

\subsection{Comparison with earlier studies}

Another study on the relation between lower stratospheric parameters (zonal mean air temperature and zonal mean zonal wind) and lunar tidal modulation of the electrojet was performed by Yamazaki et al. (2012a). They used EEJ recordings of the Addis Ababa observatory for the years 1958-2007. In general they can confirm with their independent data set the close correlation between the enhancement of the northern polar stratospheric temperature and lunar tidal amplitude. They also identify years when the correlation breaks down, but these are a minority. They confirm the correspondence in approximately $70 \%$ of the SSW events between 1958-2007.

When deducing the occurrence of an SSW event from the EEJ tidal signature a clear criterion is needed. For example, Park et al. (2012) defined a threshold for the level of wave power of the lunar tide. In their publication they demonstrated a one-to-one correspondence between actual SSW events and large enough lunar tidal signals for the years 2001-2009. It would be desirable to also find a threshold value for the wave power we deduced for Huancayo. A possibility is to estimate the threshold from the average wave power of the years from 1997-2009 when the lunitidal signatures are very clear. For this period we obtain an average value of $800 \mathrm{nT}^{2}$. We define the threshold value to be $75 \%$ of the average value, $A_{\mathrm{thr}}=600 \mathrm{nT}^{2}$. The black dashed lines in Figs. 5 and 6 mark this threshold. According to this rather simple classification we predict from the early EEJ recordings several non-SSW years. Since the frequency of major SSW events is approximately six per decade (Charlton and Polvani, 2007), this approach seems realistic. Even though 


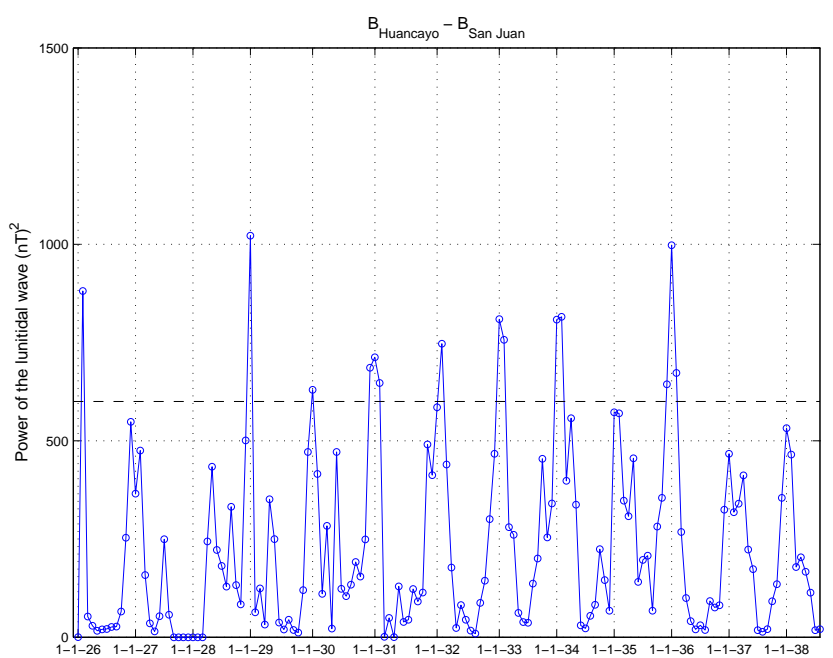

Figure 5. The figure presents the wave power of the lunar tide derived from the Huancayo-San Juan pair for the years 1926-1938. The black dashed line shows the threshold level for classifying SSW and non-SSW years.

there are uncertainties involved, these are the first estimates of SSW events before the direct observations.

\subsection{A superposed epoch analysis}

For a more quantitative assessment of the timing between the enhanced lunar tide and the SSW event, we use the method of superposed epoch analysis (SEA). The SEA method is performed on the lunar tides estimated from the Huancayo-San Juan station pair for the period of the best data quality, 19972009. It is then compared with the SEA results obtained from the zonal mean temperature gradient $\left(T_{90^{\circ} \mathrm{N}}-T_{60^{\circ} \mathrm{N}}\right.$ both at $10 \mathrm{hPa}$ ) and $U_{60}-U_{C}$ for the same time period. For our study, we define the starting day of an SSW event as the first maximum of the zonal mean temperature gradient during the northern winters. This date is taken as the key time for selecting an interval of 60 days before and 120 days after the starting day for performing the superposition. From Fig. 4 it can be seen that 13 events are available for the SEA according to our classification for the period 1997-2009. Since the wave power of the lunar tide is only sampled once per lunar cycle, we use linearly interpolated values.

Figure 7 shows the result of superposed epoch analysis. The top panel contains the composite of lunitidal wave power with a maximum around the starting day of SSW events. The second and the third panels show the composite of the zonal mean temperature gradient and $U_{60}-U_{C}$. As expected, the composite of the temperature gradient shows a sharp peak at about 1 day after the key time and a width of 5 days around the start of the SSW events. It can also be seen that the composite of the $U_{60}-U_{C}$ reaches the value of $-20 \mathrm{~m} \mathrm{~s}^{-1}$, which we used to define an SSW event. We observe that there is not much variability between the zonal mean zonal wind and the

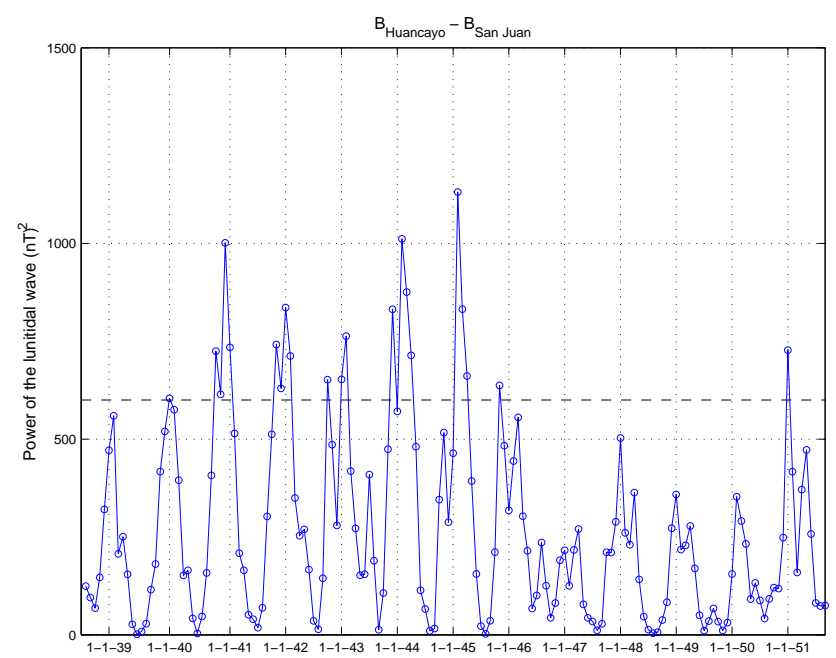

Figure 6. As Fig. 5, but for the period 1939-1951.

Table 2. Gaussian curve parameters.

\begin{tabular}{ccc}
\hline Amplitude $(\mathrm{nT})^{2}$ & $\sigma$ (days) & $\mu$ (days before SSW) \\
\hline 789 & 38 & 4.3 \\
\hline
\end{tabular}

climatology before the start of SSW events. After about a month average wind velocity reaches the normal climatological levels.

Our analysis confirms a close relation between the increase in stratospheric temperature difference and enhanced lunitidal signal. For quantifying our SEA result we fitted a Gaussian normal distribution to the wave power curve (see green dashed line in Fig. 7). The fitting results are listed in Table 2. Since an SSW event starts independently from the moon phase this approach seems justified. From the fit to the composite wave power curve we obtain the peak of the Gaussian curve $\left(A=789 \mathrm{nT}^{2}\right)$ about 4.3 days before the SSW start date and with a standard deviation of $\sigma=38$ days. The fairly large width of the distribution is partly due to the random difference between the SSW start and lunar phase, but primarily due to our long analysis interval of 59 days.

It is assumed that the lunar tidal wave originates from the lower atmosphere and propagates upward. According to Forbes and Zhang (2012) a certain atmospheric resonance peak shifts right onto the quasi-semidiurnal period $(12.42 \mathrm{~h})$ of the moon phase. This strongly supports an efficient upward propagation of the tidal wave. From the results of our superposed analysis we may conclude that the sudden change in stratospheric temperature at the North Pole immediately triggers the condition that is shifting the resonance peak. Further investigations including model simulations are probably needed to fully explain the observed relation. 

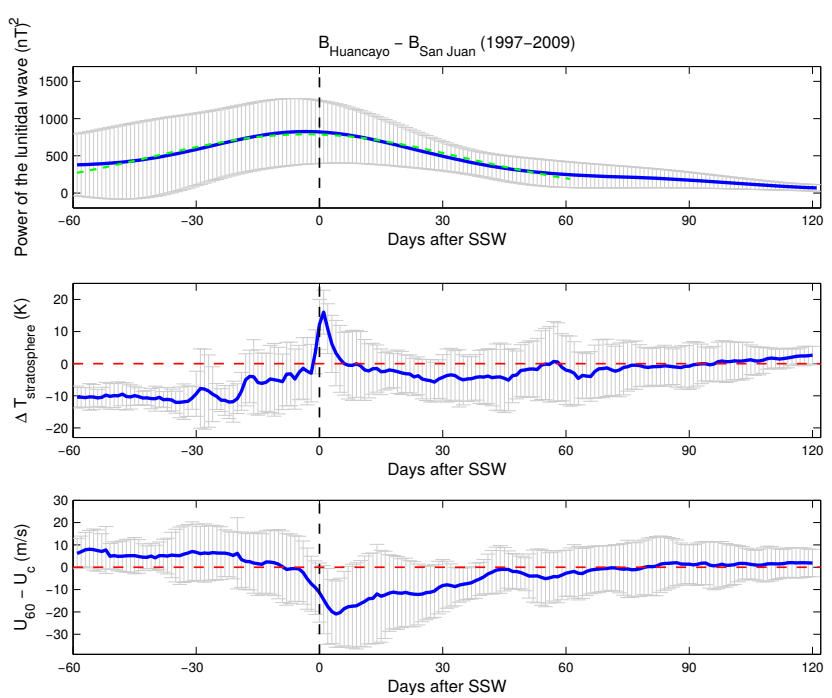

Figure 7. Results of the superposed epoch analysis: composite of the semi-monthly lunitidal wave power (top), zonal mean temperature gradient (middle) and $U_{60}-U_{C}$ (bottom) for the years 19972009. The vertical dashed lines indicate the starting day of SSW events. The error bar represents the standard deviation in all the three panels. The dotted green curve in the top frame shows the Gaussian curve fitted for 60 days each on the either side of starting date of SSW events.

\section{Conclusions}

We have used the magnetic field data of the Huancayo observatory to determine the modulation of the equatorial electrojet (EEJ) by the lunar tide. The size of tidal amplitude is compared with the occurrence of SSW events. Major points of our study are as follows.

1. A new analysis technique is used, focusing on the harmonic signal that is strictly in phase with the expected tidal wave. This helps efficiently to suppress the influence of solar activity dependent EEJ fluctuations and day-to-day variabilities.

2. As expected, large lunar tidal amplitudes are observed during northern winter months. As far as we can determine from our data analysis, peak amplitudes occur generally around times of SSW events.

3. We have investigated the relation between tidal amplitude and SSW event by means of a superposed epoch analysis. From this approach a clear relation between these two quantities arises. When the reference day for the analysis is defined by the first peak in high-latitude stratospheric temperature difference then the mean tidal amplitude peaks on average 4 days earlier. Individual years, however, exhibit tidal peaks depending on the lunar phase within a month before or after the stratospheric warming peak, which we cannot explain at the moment.
4. We also consider periods before the time of direct SSW observations (before 1952). Huancayo data from 1926 onwards are analysed. The annual variation pattern emerges after 1932. We have estimated a threshold value for the tidal wave power that may help to identify years with SSW events from magnetic field observations. Our results propose an average of approximately six SSW events per decade also before 1952.

Acknowledgements. The results presented in this paper rely on the data collected at San Juan and Huancayo. We thank US Geological Survey and Instituto Geofisico del Peru, for supporting its operation and INTERMAGNET for promoting high standards of magnetic observatory practice. We are also grateful to NOAA/OAR/ESRL PSD, Boulder, CO, for providing NCEP-NCAR reanalysis data. The solar activity index $F_{10.7}$ is provided by Herzberg Institute of Astrophysics. The sunspot number data is provided by WDCSILSO, Royal Observatory of Belgium, Brussels.

The service charges for this open-access publication have been covered by a Research Centre of the Helmholtz Association.

Topical Editor K. Hosokawa thanks two anonymous referees for their help in evaluating this paper.

\section{References}

Alken, P. and Maus, S.: Spatio-temporal characterization of the equatorial electrojet from CHAMP, Ørsted, and SACC satellite measurements, J. Geophys. Res., 112, A09305, doi:10.1029/2007JA012524, 2007.

Andrews, D. G., Holton, J. R., and Leovy, C. B.: Middle atmosphere dynamics, 40, Academic press, 1987.

Bartels, J. and Johnston, H.: Geomagnetic tides in horizontal intensity at Huancayo, Terrestrial Magnetism and Atmospheric Electricity, 45, 269-308, 1940.

Charlton, A. J. and Polvani, L. M.: A new look at stratospheric sudden warmings. Part I: Climatology and modeling benchmarks, J. Climate, 20, 449-469, 2007.

Chau, J. L., Goncharenko, L. P., Fejer, B. G., and Liu, H.-L.: Equatorial and low latitude ionospheric effects during sudden stratospheric warming events, Space Sci. Rev., 168, 385-417, 2012.

Egedal, J.: On the computation of lunar daily variations in geomagnetism: two simple methods, Det danske Meteorologiske Institut, 1956.

Fejer, B. G., Olson, M., Chau, J., Stolle, C., Lühr, H., Goncharenko, L., Yumoto, K., and Nagatsuma, T.: Lunar-dependent equatorial ionospheric electrodynamic effects during sudden stratospheric warmings, J. Geophys. Res.-Space, 115, A00G03, doi:10.1029/2010JA015273, 2010.

Fejer, B. G., Tracy, B., Olson, M., and Chau, J.: Enhanced lunar semidiurnal equatorial vertical plasma drifts during sudden stratospheric warmings, Geophys. Res. Lett., 38, L21104, doi:10.1029/2011GL049788, 2011. 
Forbes, J. M. and Zhang, X.: Lunar tide amplification during the January 2009 stratosphere warming event: Observations and theory, J. Geophys. Res.-Space, 117, A12312, doi:10.1029/2012JA017963, 2012.

Gouin, P.: Preliminary determination of the lunar diurnal influence on the geomagnetic components $\mathrm{H}, \mathrm{D}$, and $\mathrm{Z}$ at Addis Ababa, Bull. Geophys. Obs., Univ. Coll. Addis Ababa, 2, 1-8, 1960.

Kalnay, E., Kanamitsu, M., Kistler, R., Collins, W., Deaven, D., Gandin, L., Iredell, M., Saha, S., White, G., Woollen, J., Zhu, Y., Leetmaa, A., Reynolds R., Chelliah, M., Ebisuzaki, W., Higgins, W., Janowiak, J., Mo, K. C., Ropelewski, C., Wang, J., Jenne, R., and Joseph, D.: The NCEP/NCAR 40-year reanalysis project, B. Am. Meteorol. Soc., 77, 437-471, 1996.

Lühr, H., Rother, M., Häusler, K., Alken, P., and Maus, S.: The influence of nonmigrating tides on the longitudinal variation of the equatorial electrojet, J. Geophys. Res.-Space, 113, A08313, doi:10.1029/2008JA013064, 2008.

Lühr, H., Siddiqui, T. A., and Maus, S.: Global characteristics of the lunar tidal modulation of the equatorial electrojet derived from CHAMP observations, Ann. Geophys., 30, 527-536, doi:10.5194/angeo-30-527-2012, 2012.

Manoj, C., Lühr, H., Maus, S., and Nagarajan, N.: Evidence for short spatial correlation lengths of the noontime equatorial electrojet inferred from a comparison of satellite and ground magnetic data, J. Geophys. Res.-Space, 111, A11312, doi:10.1029/2006JA011855, 2006.

Matsuno, T.: A dynamical model of the stratospheric sudden warming, J. Atmos. Sci., 28, 1479-1494, 1971.

Onwumechilli, A.: Lunar daily variation of the magnetic declination at Ibadan, Nigeria, J. Geophys. Res., 65, 3433-3435, 1960.

Park, J., Lühr, H., Kunze, M., Fejer, B. G., and Min, K. W.: Effect of sudden stratospheric warming on lunar tidal modulation of the equatorial electrojet, J. Geophys. Res., 117, A03306, doi:10.1029/2011JA017351, 2012.
Rastogi, R. and Trivedi, N.: Luni-solar tides in $H$ at stations within the equatorial electrojet, Planet. Space Sci., 18, 367-377, 1970.

Richards, P., Fennelly, J., and Torr, D.: EUVAC: A solar EUV flux model for aeronomic calculations, J. Geophys. Res.-Space, 99, 8981-8992, 1994.

Scherhag, R.: Die explosionsartigen Stratosphärenerwärmungen des Spätwinters 1951/52, Berichte des deutschen Wetterdienstes in der US-Zone, 6, 51-63, 1952.

Stening, R.: What drives the equatorial electrojet?, J. Atmos. Terr. Phy., 57, 1117-1128, 1995.

Stening, R.: Lunar tide in the equatorial electrojet in relation to stratospheric warmings, J. Geophys. Res.-Space, 116, A12315, doi:10.1029/2011JA017047, 2011.

Stolle, C., Manoj, C., Lühr, H., Maus, S., and Alken, P.: Estimating the daytime Equatorial Ionization Anomaly strength from electric field proxies, J. Geophys. Res.-Space, 113, A09310, doi:10.1029/2007JA012781, 2008.

Yamazaki, Y.: Large lunar tidal effects in the equatorial electrojet during northern winter and its relation to stratospheric sudden warming events, J. Geophys. Res.-Space, 118, 7268-7271, 2013.

Yamazaki, Y., Richmond, A., and Yumoto, K.: Stratospheric warmings and the geomagnetic lunar tide: 1958-2007, J. Geophys. Res.-Space, 117, A04301, doi:10.1029/2012JA017514, 2012a.

Yamazaki, Y., Yumoto, K., McNamara, D., Hirooka, T., Uozumi, T., Kitamura, K., Abe, S., and Ikeda, A.: Ionospheric current system during sudden stratospheric warming events, J. Geophys. Res.Space, 117, A03334, doi:10.1029/2011JA017453, 2012b. 